\title{
Study on the Awareness and Demands of Korean University Students Majoring in Physical Therapy: Focus on Women's Health Physical Therapy
}

\author{
Jin-Su Kim $\cdot$ Han-Suk Lee, PT, $\mathrm{PhD}^{1 \dagger} \cdot \mathrm{Mi}-$ Rim Song $\cdot \mathrm{Ji}-$ Min Yu $\cdot$ Jae-Eun Hur \\ Undergraduate student, Department of Physical Therapy, Eulji University, \\ ${ }^{1}$ Department of Physical Therapy, Eulji University
}

Received: April 12, 2021 / Revised: April 13, 2021 / Accepted: April 28, 2021

(C) 2021 J Korean Soc Phys Med

\section{| Abstract |}

PURPOSE: This study examined the awareness and demands for Women's Health Physical Therapy (WHPT) of university students majoring in physical therapy.

METHODS: From September to October 2020, questionnaire surveys were distributed to students majoring in physical therapy using a convenience sampling method. Data were collected via an internet form from 300 students in eight universities. The survey consisted of three parts consisting of five general characteristics, four questions for awareness, and five questions for the demands. The numerical values for the questions were calculated using a Likert-type scale and descriptive statistics. An independent T-test, ANOVA, and Dunnett T3 test were performed, and the significance level was .05.

RESULTS: The demands (3.88) level of the WHPT was higher than the awareness (2.32). The awareness was similar in both genders $(\mathrm{p}>.05)$, but there was a significant difference in the demand between genders $(p<.05)$. Female students knew better and had more demands of WHPT than male

$\dagger$ Corresponding Author : Han-Suk Lee leehansuk21@hanmail.net, https://orcid.org/0000-0002-9336-0894 This is an Open Access article distributed under the terms of the Creative Commons Attribution Non-Commercial License (http://creativecommons.org/licenses/by-nc/3.0) which permits unrestricted non-commercial use, distribution, and reproduction in any medium, provided the original work is properly cited. students. Similarly, a difference in the awareness level by grade was found. The $4^{\text {th }}$ grade had the highest awareness comparing the $1^{\text {st }}, 2^{\text {nd }}$, and $3^{\text {rd }}$ grades, but there was no significant difference in awareness and demand according to clinical practice $(\mathrm{p}>.05)$.

CONCLUSION: The students have high demands compared to awareness, suggesting that the university and association need to prepare diverse and deeper education on WHPT.

Key Words: Women, Physical therapy, Health education

\section{Introduction}

According to the Korea National Statistical Office data survey (2020), women accounted for 49.88 percent (25.82 million) of the population in Korea in 2019 [1]. Women's health, which accounts for approximately half of Korea's total population, is becoming a vital health area in terms of the scale occupied by women and the health problems of future generations [2]. Women's health is an essential condition for a happy life [3] and is connected to the health of the whole people.

Women are exposed to various diseases, such as genitourinary system diseases, obesity, and cancer (breast cancer, uterine cancer). Urinary incontinence of the genitourinary 
Table 1. General Characteristics of the Participants

\begin{tabular}{cccc}
\hline Items & Characteristics & $\mathrm{N}$ & $\%$ \\
\hline \multirow{2}{*}{ Gender } & Male & 113 & 37.70 \\
& Female & 187 & 62.30 \\
\hline \multirow{2}{*}{ Grade } & 1 & 74 & 24.70 \\
& 2 & 74 & 24.70 \\
& 3 & 123 & 41.00 \\
& 4 & 29 & 9.70 \\
\hline \multirow{2}{*}{ Clinical practice experience } & Yes & 68 & 22.70 \\
& No & 232 & 77.30 \\
\hline
\end{tabular}

$\mathrm{N}$ : Number of students

system is a common disease experienced by $25 \%$ of women before menopause and $40 \%$ of women after menopause. The incidence is increasing gradually in modern times [4]. In addition, breast cancer has continued to increase in women of all ages, with an incidence of 286.8 per one hundred thousand people, increasing $2.2 \%$ compared to 2016 [5]. Moreover, more than $50 \%$ of women complained of back pain after childbirth [6]. Therefore, physical therapists should accurately recognize women's health problems and play a professional role in following women's health needs.

Currently, physical therapy in Korea has dealt with women's diseases, including urinary incontinence, breast cancer, and pregnant women with back pain. On the other hand, postpartum care for women with back pain has not been managed properly [7]. In contrast to Korea, physical therapists in the United States of America (USA) provide specific therapy to females for each period of childbirth. Therefore, it is necessary to provide specific therapy for women's diseases in Korea.

The Korean Physical Therapists Association established the Pelvic and Women's Health Physical Therapy academy related to women's physical therapy similar to the USA[8]. Nevertheless, educational programs related to women's physical therapy organized by the Pelvic and WHPT (Women's Health Physical Therapy) Academy were not spread widely in Korea. Therefore, students have lacked the opportunity to obtain information on WHPT.

Although the subjects of WHPT were added to the 2020's National Examination for Physical Therapist [9], there is a lack of professional women's health therapy education for undergraduates of physical therapy. Only the physical therapy department of Hoseo University has a subject related to WHPT.

Therefore, this study examined how students understand and require WHPT quantitatively to provide basic data for education and research.

\section{Methods}

\section{Participants and data collection methods}

The survey was completed by 300 students majoring in physical therapy from eight out of 46 four-year universities across the country from September to October 2020. The participants were conveniently recruited, and the survey data were collected online. Before collecting the data, the purpose of the study and the questionnaire completion method were explained to the participants, who then signed a consent form to participate in the study.

The characteristics of those who participated in this study were as follows: 113 were male $(37.70 \%)$ and 187 were female $(62.30 \%)$. The participants were divided into $1^{\text {st }}$ 
graders $(24.70 \%), 2^{\text {nd }}$ graders $(24.70 \%), 3^{\text {rd }}$ graders $(41.00 \%)$, and $4^{\text {th }}$ graders $(9.70 \%)$. Sixty-eight of the participants $(22.70 \%)$ said they had experienced clinical practice (Table 1).

\section{Survey Development}

After reviewing the literature, the questionnaire used by Hong(2018) [11] and Seo and $\operatorname{Kim}(2019)$ [12] was modified and supplemented to match the characteristics of WHPT. The draft consisted of six questions on the general characteristics, four questions on awareness, and five questions about demand. A professor in physical therapy was then consulted; the questionnaire was composed of five questions, each about the general characteristics, awareness, and demand. After the first survey for 40 people for three days, the questionnaire was finally revised. One question of awareness was eliminated.

Except for the general characteristics, a Likert's 5-point scale was used: "Not at all" was 1, and "Very Yes" was 5 points. The Likert's 5-point scale was not used for items for the Paths of Awareness and Areas for WHPT, Related Subjects, Problems during Treatment, Methods of Improving Awareness, Needs, and Reasons for Hoping employment.

\section{Data Analysis}

All questions of the general characteristics and WHPT were conducted according to an analysis of frequency. The means (Standard Deviation) of the questions using the Likert scale were calculated using descriptive statistics. An independent sample t-test was performed to compare the difference between genders and between the clinical practice experience. ANOVA (Analysis of Variance) was performed to compare the differences between grades, and Dunnett's T3 was used for the post-hoc test. SPSS 20.0(Korea IBM) was used to analyze the data collected in this study, and the significance level was set to .05 .

\section{Results}

\section{Awareness of University Students Majoring in} Physical Therapy about WHPT

Among the five questions related to awareness about WHPT, the question 'How much do students know about WHPT(awareness of WHPT)' produced a low score (2.32 \pm .90 ). The highest way to obtain information on WHPT was education from university at $38.710 \%$. The most knowledgeable area of WHPT was pregnancy and childbirth $(74.19 \%)$. For the problem in providing WHPT, students responded that they did not know any difference from general physical therapy (40.33\%). A significant proportion of respondents $(36.67 \%)$ answered that the formation of a curriculum is needed to improve the awareness of WHPT. The students thought that the role of the physical therapist in treating women's diseases was important $(4.01 \pm .76)($ Table 2$)$.

\section{Demands of University Students Majoring in Physical Therapy about WHPT}

The demand for WHPT was high (scored $3.88 \pm .86$ ). Further questions on the need for WHPT were given to 212 students who answered positively about the demand for WHPT care. The highest response rate was because they want to provide high-quality care $(58.96 \%)$. The question regarding the necessity of WHPT was given to 15 students who answered negatively about the demand for WHPT, they answered that general physical therapy was sufficient $(66.67 \%)$.

The sufficiency of university education and clinical practice about WHPT was low $(2.41 \pm .80)$. The willingness to participate in WHPT education scored $3.77 \pm .88$. The intention to engage in WHPT scored $3.18 \pm .99$. The outlook of WHPT scored $3.83 \pm .75$. They wanted to work in WHPT because they wanted to experience the field of WHPT (91.59\%). The students who answered not willing to work in this area responded they were not interested (95.08\%) 
Table 2. Awareness of Women's Health Physical Therapy

$\mathrm{N}=300$

\begin{tabular}{|c|c|c|c|c|}
\hline \multicolumn{3}{|c|}{ Item } & \multicolumn{2}{|c|}{$\mathrm{M} \pm \mathrm{SD}$} \\
\hline 1 & \multicolumn{2}{|c|}{ Awareness of WHPT (How much do you know about WHPT) } & \multicolumn{2}{|c|}{$2.32 \pm .90$} \\
\hline \multicolumn{3}{|c|}{ Sub-item of awareness of WHPT } & $\mathrm{N}$ & $\%$ \\
\hline & \multirow{6}{*}{ 1-1. Way to get information about WHPT } & Internet/TV & 11 & 35.48 \\
\hline & & University education & 12 & 38.71 \\
\hline & & Book/Newspaper & 3 & 9.68 \\
\hline & & Lecture & 3 & 9.68 \\
\hline & & Other & 2 & 6.45 \\
\hline & & Subtotal & 31 & 100.00 \\
\hline & \multirow{6}{*}{ 1-2. Field of WHPT that participants know } & Pregnancy and childbirth & 23 & 74.19 \\
\hline & & Genital and gastrointestinal disease & 6 & 19.36 \\
\hline & & Obesity & 2 & 6.45 \\
\hline & & Cancer & 0 & .00 \\
\hline & & Urinary & 0 & .00 \\
\hline & & Subtotal & 31 & 100.00 \\
\hline \multirow{5}{*}{2} & \multirow{5}{*}{ Problem in providing WHPT } & No difference from general physical therapy & 121 & 40.33 \\
\hline & & Lack of specialist of WHPT & 94 & 31.33 \\
\hline & & Lack of information about women disease & 76 & 25.33 \\
\hline & & Cost & 5 & 1.67 \\
\hline & & Other & 4 & 1.33 \\
\hline \multirow{5}{*}{3} & \multirow{5}{*}{ Ways to improve the awareness of WHPT } & Curriculum formation & 110 & 36.67 \\
\hline & & Workshop with other areas & 74 & 24.67 \\
\hline & & Advertising via media & 62 & 20.67 \\
\hline & & Professional certificate system & 52 & 17.33 \\
\hline & & Other & 2 & .67 \\
\hline 4 & \multicolumn{2}{|c|}{ The importance of the role of physical therapists in the treatment of women's disease } & \multicolumn{2}{|c|}{$4.01 \pm .76$} \\
\hline
\end{tabular}

N: Number of students, M: Mean, SD: Standard Deviation, WHPT: Women's Health Physical Therapy

and a low awareness of WHPT $(4.92 \%)$ (Table 3).

3. Difference according to the general characteristics

1) Difference of awareness and demands of WHPT according to gender

There was no significant difference in the awareness and importance of the role of physical therapists of WHPT between $(\mathrm{t}=-2.197, \mathrm{p}=.521, \mathrm{t}=.685, \mathrm{p}=.408)$. There was a significant difference between genders for the demands of WHPT $(\mathrm{t}=8.423, \mathrm{p}=.004)$. On the other hand, there was no significant difference in the sufficiency of university education and clinical practice $(t=-.291$, $\mathrm{p}=.892)$ between genders. The willingness to participate in WHPT education showed a significant difference $(t=$ $-6.914, \mathrm{p}=.000$ ) between genders. In addition, the question of the intention of working in the WHPT after graduation had a significant difference $(t=-8.493, p=.023)$ between genders. Finally, the response to the outlook of WHPT also showed significant differences between genders $(t=$ $-3.024, \mathrm{p}=.004)($ Table 4). 


\begin{tabular}{|c|c|c|c|}
\hline \multicolumn{2}{|r|}{ Item } & \multicolumn{2}{|c|}{$\mathrm{M} \pm \mathrm{SD}$} \\
\hline 1 & Demands about the need for WHPT & \multicolumn{2}{|c|}{$3.88 \pm .86$} \\
\hline & Sub-item of demand for WHPT & $\mathrm{N}$ & $\%$ \\
\hline & \multirow{5}{*}{$\begin{array}{c}1-1 . \\
\text { Reason why WHPT is necessary }\end{array}$} & 125 & 58.96 \\
\hline & & 61 & 28.77 \\
\hline & & 16 & 7.55 \\
\hline & & 10 & 4.72 \\
\hline & & 212 & $100.00 \%$ \\
\hline & General physical therapy is enough & 10 & 66.67 \\
\hline & Systematic program not developed & 2 & 13.33 \\
\hline & Limitations of care program & 2 & 13.33 \\
\hline & Negative outlook & 1 & 6.67 \\
\hline & Subtotal & 15 & $100.00 \%$ \\
\hline & Item & \multicolumn{2}{|c|}{$\mathrm{M} \pm \mathrm{SD}$} \\
\hline 2 & Sufficiency of school education and clinical practice about WHPT & \multicolumn{2}{|c|}{$2.41 \pm .80$} \\
\hline 3 & Willingness to participate in WHPT education & \multicolumn{2}{|c|}{$3.77 \pm .88$} \\
\hline 4 & Outlook of WHPT & \multicolumn{2}{|c|}{$3.83 \pm .75$} \\
\hline 5 & Intention to engage in the fields related to WHPT after graduation & \multicolumn{2}{|c|}{$3.18 \pm .99$} \\
\hline & Sub-item of intention to engage in the field related to WHPT after graduation & $\mathrm{N}$ & $\%$ \\
\hline & To experience the field of WHPT & 98 & 91.59 \\
\hline & \multirow{3}{*}{$\begin{array}{cc}5-1 & \text { For financial reasons } \\
\text { Reasons why they wanted to work in WHPT } & \text { Low competition rate } \\
& \text { For postgraduate course }\end{array}$} & 4 & 3.74 \\
\hline & & 3 & 2.80 \\
\hline & & 2 & 1.87 \\
\hline & Subtotal & 107 & $100.00 \%$ \\
\hline & \multirow{3}{*}{$\begin{array}{l}5-2 \\
\text { Reasons why they are not wanted to work in WHPT }\end{array}$} & 58 & 95.08 \\
\hline & & 3 & 4.92 \\
\hline & & 61 & $100.00 \%$ \\
\hline
\end{tabular}

N: Number of students, M: Mean, SD: Standard Deviation, WHPT: Women's Health Physical Therapy

2) Difference in the awareness and demands of WHPT depending on the Student's Grade

Significant differences in questions about awareness of WHPT $(\mathrm{F}=8.148, \mathrm{p}=.000)$ among grades were observed. A Dunnett's T3 test was used for post-analysis to identify the difference in grade; $4^{\text {th }}$ grade had higher awareness than 2nd and 3rd grades. On the other hand, the awareness about the importance of the physical therapist's role in women's disease treatment was similar among grades ( $t$
$=.742, \mathrm{p}=.528)$.

The demand for WHPT had a significant difference according to grade $(\mathrm{F}=-.985, \mathrm{p}=.032)$. Post-analysis showed a significant difference between 1st grade and 3rd grade. Moreover, the sufficiency of university education and clinical practice in WHPT showed a significant difference $(\mathrm{F}=8.008, \mathrm{p}=.000)$. The result of post-analysis showed that $1^{\text {t }}$ grade was higher than $2^{\text {nd }}, 3^{\text {nd }}$, and $4^{\text {th }}$ grades. The willingness to participate in WHPT education showed a significant difference; $1^{\text {st }}$ grade was higher than $3^{\text {rd }}$ grade 
Table 4. Difference Awareness and Demands According to Gender

\begin{tabular}{|c|c|c|c|c|c|}
\hline Category & Gender & N (\%) & $\mathrm{M} \pm \mathrm{SD}$ & $\mathrm{t}$ & $\mathrm{p}$ \\
\hline \multirow{2}{*}{ Awareness of WHPT } & Male & $113(37.70)$ & $2.18 \pm .93$ & \multirow{2}{*}{-2.197} & \multirow{2}{*}{.521} \\
\hline & Female & $187(62.30)$ & $2.41 \pm .88$ & & \\
\hline \multirow{2}{*}{ Awareness of physical therapist's role in the treatment of women's disease } & Male & $113(37.70)$ & $3.85 \pm .78$ & \multirow{2}{*}{-2.821} & \multirow{2}{*}{.408} \\
\hline & Female & $187(62.30)$ & $4.10 \pm .73$ & & \\
\hline \multirow{2}{*}{ Demands for WHPT } & Male & $113(37.70)$ & $3.70 \pm .93$ & \multirow{2}{*}{-2.908} & \multirow{2}{*}{$.004 *$} \\
\hline & Female & $187(62.30)$ & $4.00 \pm .80$ & & \\
\hline \multirow{2}{*}{ Sufficiency of school education and clinical practice in WHPT } & Male & $113(37.70)$ & $2.39 \pm .80$ & \multirow{2}{*}{-.291} & \multirow{2}{*}{.892} \\
\hline & Female & $187(62.30)$ & $2.42 \pm .80$ & & \\
\hline \multirow{2}{*}{ Willingness to participate in WHPT education } & Male & $113(37.70)$ & $3.35 \pm .99$ & \multirow{2}{*}{-6.914} & \multirow{2}{*}{$.000^{*}$} \\
\hline & Female & $187(62.30)$ & $4.03 \pm .69$ & & \\
\hline \multirow{2}{*}{ After graduation, intention to engage in the fields related to WHPT } & Male & $113(37.70)$ & $2.62 \pm 1.00$ & \multirow{2}{*}{-8.493} & \multirow{2}{*}{$.023 *$} \\
\hline & Female & $187(62.30)$ & $3.52 \pm .81$ & & \\
\hline \multirow{2}{*}{ Outlook of WHPT } & Male & $113(37.70)$ & $3.66 \pm .79$ & \multirow{2}{*}{-3.024} & \multirow{2}{*}{$.004 *$} \\
\hline & Female & $187(62.30)$ & $3.93 \pm .71$ & & \\
\hline
\end{tabular}

$\mathrm{N}$ : Number of students, M: Mean, SD: Standard Deviation, WHPT: Women's Health Physical Therapy, ${ }^{*} \mathrm{p}<.05$

$(\mathrm{F}=4.353, \mathrm{p}=.005)$. On the other hand, there was no significant difference in the intention to engage in WHPT after graduation $(\mathrm{F}=2.606, \mathrm{p}=.052)$ and the outlook of WHPT $(\mathrm{F}=1.175, \mathrm{p}=.319)($ Table 5).

3) Difference in the awareness and demands of WHPT depending on the clinical practice experience

There was no significant difference in the awareness and demands in all questions according to clinical practice experience students $(p<.05)($ Table 6$)$. The students who had a clinical practice experience scored higher in the awareness of WHPT, the importance of the role of therapy of women's disease, demands about the need for WHPT, and outlook of WHPT than those who did not. On the other hand, the difference was not significant $(\mathrm{p}<.05)$ (Table 6).

In contrast, the students who did not have a clinical practice experience scored higher in the sufficiency of school education and clinical practice in WHPT, willingness to participate in WHPT education, and the intention to engage in the fields related to WHPT than those who had a clinical practice experience. On the other hand, the difference was not significant $(\mathrm{p}<.05)$ (Table 6).

\section{Discussion}

The number of students majoring in physical therapy awareness of WHPT was low, but their demands for WHPT were high. This means that students are unfamiliar with WHPT, but they think that physical therapists play an important role in women's health.

The four items among the five questions of demands scored above three points: the demands about WHPT, willingness to participate in WHPT education, outlook of WHPT, and intention to engage in the fields related to WHPT. These results suggest that students have interests in WHPT but did not have to opportunity to know more about it.

The highest response rate about the fields related to 
Table 5. Difference in the WHPT Awareness and Demands According to the Student's Grade N = 300

\begin{tabular}{|c|c|c|c|c|c|c|}
\hline Category & Grade & $\mathrm{N}$ & $\mathrm{M} \pm \mathrm{SD}$ & $\mathrm{F}$ & $\mathrm{p}$ & Dunnett T3 \\
\hline \multirow{4}{*}{ Awareness of WHPT } & $1^{\mathrm{a}}$ & 74 & $2.37 \pm .93$ & \multirow{4}{*}{8.148} & \multirow{4}{*}{$.000^{*}$} & \multirow{4}{*}{$\begin{array}{l}d>b \\
d>c\end{array}$} \\
\hline & $2^{b}$ & 74 & $2.03 \pm .76$ & & & \\
\hline & $3^{\mathrm{c}}$ & 123 & $2.33 \pm .85$ & & & \\
\hline & $4^{\mathrm{d}}$ & 29 & $2.97 \pm 1.05$ & & & \\
\hline \multirow{4}{*}{$\begin{array}{l}\text { The importance of the role of the physical therapist } \\
\text { in the therapy of women's disease }\end{array}$} & 1 & 74 & $4.10 \pm .62$ & \multirow{4}{*}{.742} & \multirow{4}{*}{.528} & \\
\hline & 2 & 74 & $3.96 \pm .77$ & & & \\
\hline & 3 & 123 & $3.96 \pm .77$ & & & \\
\hline & 4 & 29 & $4.10 \pm .86$ & & & \\
\hline \multirow{4}{*}{ Demands about need of WHPT } & $1^{\mathrm{a}}$ & 74 & $4.08 \pm .66$ & \multirow{4}{*}{2.985} & \multirow{4}{*}{$.032 *$} & \multirow{4}{*}{$a>c$} \\
\hline & $2^{b}$ & 74 & $3.78 \pm .96$ & & & \\
\hline & $3^{c}$ & 123 & $3.77 \pm .88$ & & & \\
\hline & $4^{\mathrm{d}}$ & 29 & $4.10 \pm .94$ & & & \\
\hline \multirow{4}{*}{$\begin{array}{l}\text { Sufficiency of school education and clinical practice } \\
\text { in WHPT }\end{array}$} & $1^{\mathrm{a}}$ & 74 & $2.77 \pm .75$ & \multirow{4}{*}{8.008} & \multirow{4}{*}{$.000^{*}$} & \multirow{4}{*}{$\begin{array}{l}a>b \\
a>c \\
a>d\end{array}$} \\
\hline & $2^{\mathrm{b}}$ & 74 & $2.38 \pm .77$ & & & \\
\hline & $3^{c}$ & 123 & $2.27 \pm .76$ & & & \\
\hline & $4^{\mathrm{d}}$ & 29 & $2.14 \pm .88$ & & & \\
\hline \multirow{4}{*}{ Willingness to participate in WHPT education } & $1^{\mathrm{a}}$ & 74 & $4.05 \pm .74$ & \multirow{4}{*}{4.353} & \multirow{4}{*}{$.005^{*}$} & \multirow{4}{*}{$a>c$} \\
\hline & $2^{\mathrm{b}}$ & 74 & $3.81 \pm .79$ & & & \\
\hline & $3^{\mathrm{c}}$ & 123 & $3.63 \pm .91$ & & & \\
\hline & $4^{\mathrm{d}}$ & 29 & $3.55 \pm 1.12$ & & & \\
\hline \multirow{4}{*}{$\begin{array}{c}\text { Intention to engage in the fields related WHPT } \\
\text { after graduation }\end{array}$} & 1 & 74 & $3.45 \pm .83$ & \multirow{4}{*}{2.606} & \multirow{4}{*}{.052} & \\
\hline & 2 & 74 & $3.10 \pm .91$ & & & \\
\hline & 3 & 123 & $3.12 \pm 1.07$ & & & \\
\hline & 4 & 29 & $2.97 \pm 1.12$ & & & \\
\hline \multirow{4}{*}{ Outlook of WHPT } & 1 & 74 & $3.95 \pm .64$ & \multirow{4}{*}{1.175} & \multirow{4}{*}{.319} & \\
\hline & 2 & 74 & $3.78 \pm .73$ & & & \\
\hline & 3 & 123 & $3.76 \pm .81$ & & & \\
\hline & 4 & 29 & $3.93 \pm .80$ & & & \\
\hline
\end{tabular}

N: Number of students, M: Mean, SD: Standard Deviation, Dunnet T3: post-hoc analysis,

WHPT: Women's Health Physical Therapy, *p $<.05$

WHPT was pregnancy and childbirth-related fields (74.19\%). Other responses, such as genital and gastrointestinal diseases $(19.36 \%)$ or obesity $(6.45 \%)$, were recorded, but there was no response of cancer or urinary incontinence. Hence, students comprehend WHPT as primarily related to pregnancy and childbirth. Urinary incontinence and cancer are also important fields of WHPT, but there is a lack of awareness about them.

The highest response rate about problems in providing WHPT was no different from general physical therapy 
Table 6. Difference in the Awareness and Demands of WHPT According to CPE

\begin{tabular}{|c|c|c|c|c|c|}
\hline Category & $\mathrm{CPE}$ & N (\%) & $\mathrm{M} \pm \mathrm{SD}$ & $\mathrm{t}$ & $\mathrm{p}$ \\
\hline \multirow{2}{*}{ Awareness of WHPT } & $\mathrm{Y}$ & $68(22.70)$ & $2.53 \pm .95$ & \multirow{2}{*}{2.154} & \multirow{2}{*}{.312} \\
\hline & $\mathrm{N}$ & $232(77.30)$ & $2.26 \pm .88$ & & \\
\hline \multirow{2}{*}{$\begin{array}{l}\text { The importance of the role of the physical therapist } \\
\text { in the treatment of women's disease }\end{array}$} & Y & $68(22.70)$ & $4.15 \pm .80$ & \multirow{2}{*}{1.742} & \multirow{2}{*}{.090} \\
\hline & $\mathrm{N}$ & $232(77.30)$ & $3.97 \pm .74$ & & \\
\hline \multirow{2}{*}{ Demands about need of WHPT } & $\mathrm{Y}$ & $68(22.70)$ & $4.03 \pm .83$ & \multirow{2}{*}{1.590} & \multirow{2}{*}{.213} \\
\hline & $\mathrm{N}$ & $232(77.30)$ & $3.84 \pm .87$ & & \\
\hline \multirow{2}{*}{ Sufficiency of school education and clinical practice in WHPT } & $\mathrm{Y}$ & $68(22.70)$ & $2.31 \pm .87$ & \multirow{2}{*}{-1.150} & \multirow{2}{*}{.490} \\
\hline & $\mathrm{N}$ & $232(77.30)$ & $2.44 \pm .78$ & & \\
\hline \multirow{2}{*}{ Willingness to participate in WHPT education } & Y & $68(22.70)$ & $3.63 \pm .96$ & \multirow{2}{*}{-1.509} & \multirow{2}{*}{.167} \\
\hline & $\mathrm{N}$ & $232(77.30)$ & $3.82 \pm .85$ & & \\
\hline \multirow{2}{*}{ Intention to engage in the fields related WHPT after graduation } & $\mathrm{Y}$ & $68(22.70)$ & $3.07 \pm 1.11$ & \multirow{2}{*}{-1.010} & \multirow{2}{*}{.577} \\
\hline & $\mathrm{N}$ & $232(77.30)$ & $3.21 \pm .95$ & & \\
\hline \multirow{2}{*}{ Outlook of WHPT } & $\mathrm{Y}$ & $68(22.70)$ & $3.91 \pm .75$ & \multirow{2}{*}{1.022} & \multirow{2}{*}{.750} \\
\hline & $\mathrm{N}$ & $232(77.30)$ & $3.81 \pm .75$ & & \\
\hline
\end{tabular}

$\mathrm{N}$ : Number of students, M: Mean, SD: Standard Deviation,

CPE: Clinical Practice Experience, WHPT: Women's Health Physical Therapy, ${ }^{*} \mathrm{p}<.05$

(40.33\%). In many countries, specialized nurses handle urinary incontinence with professional training. There are also specialized physical therapists of WHP. In the USA, a "Continence advisor" is a professional nurse for patients with urinary incontinence problems. Similar to a professional nurse, a "Pelvic floor physical therapist" is a professional physical therapist related to WHPT $[13,14]$. Pelvic floor physical therapists treat diseases, including urinary incontinence, using manual therapy. Their therapy helps improve women's quality of life. Graduate-level education and institution curriculum has been developed for professional Pelvic floor physical therapy in the USA. In contrast, the treatment of urinary incontinence in Korea is done only by the individual choice of patients, not by therapists [15].

The next highest response rate of problems in providing WHPT was a lack of information about women's diseases $(25.33 \%)$. This result is similar to the findings of Kim Un-yong [16] in that most breast cancer patients do not receive information about the disease. Park reported that female patients are not treated, even though there are various urinary incontinence treatments [17]. Most pregnant women are not treated for back pain during pregnancy [18], and there is a lack of information on physical therapy compared to high interest in breast cancer [19].

These studies show that a woman considers the women's disease as a natural and common symptom that occurs only in women despite various treatments. Therefore, women do not have sufficient information about their disease.

No significant differences in the awareness of WHPT were observed between genders, but there were significant differences in the demand about the need for WHPT. The highest response rate in fields of WHPT that participants know was pregnancy and childbirth. This means that the students about WHPT need to focus on events, such as pregnancy and childbirth. Female students are in higher demand than male students because pregnancy and 
childbirth are the most important events in a woman's life cycle. Although pregnancy and childbirth are common issues between women and men, the complications from pregnancy and childbirth are a firsthand issue for women [20]. According to Kim et al., female college students in healthcare fields thought that childbirth is a "physical and mental burden" for women [21]. Most female students think they can experience pregnancy and childbirth in the future, so they might be interested in pregnancy and childbirth as much as they are afraid. Moreover, women are more active in medical use and taking care of their health than men because of childbirth, pregnancy, and female-specific reproductive diseases [22]. Therefore, there was no difference in the awareness of WHPT between genders, but there were differences in demand.

The awareness of WHPT among grades was highest in 4th grade $(2.97 \pm 1.05)$. Regarding the medium for obtaining information about WHPT, Internet/TV was the highest in $1^{\text {st }}, 2^{\text {nd }}$ and $3^{\text {rd }}$ grades. On the other hand, undergraduate education was the highest in $4^{\text {th }}$ grade. The $4^{\text {th }}$ grade would have had more opportunities to obtain information on WHPT in various ways, including clinical practice in hospitals, various volunteer activities, and special lectures than the lower grades. Therefore, the awareness could be higher than that of the lower grades.

Students answered positively to the intention to work in the field of WHPT after graduation $(3.18 \pm .99)$. Nevertheless, the sufficiency of university education and clinical practice about WHPT scored only $2.41 \pm .80$. This means that the students do not have enough education and clinical practice experience in university, despite their willingness to work in the field of WHPT after graduation. This result is in contrast to Kim et al.[23], who reported that the student's satisfaction with clinical practice scored 3.62. On the other hand, Kim et al. investigated the satisfaction with the comprehensive areas of clinical practice of physical therapy, not the clinical practice related to WHPT. This can explain the difference between Kim et al. and the present study. Therefore, most universities have sufficient clinical practice opportunities and education for students, but clinical practice and education system were insufficient for specialized fields such as WHPT.

The willingness to participate in the women's health education scored $3.77 \pm .88$, and $36.67 \%$ of the respondents answered that the curriculum formation is necessary to improve the awareness of WHPT.

Thus, a search of the curriculum of the department of physical therapy was performed. No subject on WHPT was found in the curriculum of universities in contrast to student willingness except for Hoseo university. Therefore, universities consider inserting the education program of WHPT in their curriculum.

The way to obtain information on WHPT was approximately $3 \%$ higher for university education (38.71\%) than the Internet/TV (35.48\%). This shows that education about WHPT in university is important.

Park reported experience affects more than the student's knowledge when choosing jobs after graduation [24]. Furthermore, students have the opportunity to understand physical therapists and gain information on various fields of physical therapy, including WHPT, through clinical practice [25].

Thus, this paper highlights the need for education in universities and clinical practice programs for students that included a program of WHPT, such as pelvic floor exercise.

This study had some limitations. First, the sample size was small. Therefore, it is difficult to generalize the results to all students majoring in physical therapy. Second, the demand and awareness of physical therapists were not considered. Thus, there is a limitation in interpreting the result. Future research will be needed to compare and analyze the awareness and demands of WHPT for students majoring in physical therapy and physical therapists. 


\section{Conclusion}

Students majoring in physical therapy who participated in the survey showed that the demand for WHPT was high, but the awareness was low. This suggests that students have less opportunity despite being willing to learn. Therefore, an education program of WHPT should be reflected in the program of the association and the university.

\section{Acknowledgments}

This research was supported by a 2021 Eulji University Innovation Support Project grant

\section{References}

[1] KOSIS (National Statistical Office: Population census, 2020. https://kosis.kr/eng

[2] Ahn SH, Lee EJ, JUN EM, et al. Research trend of women's health in Korean nursing journals (2010-2015). KJWHN. 2018;24(3):276-86.

[3] Ahn MO. Life-cycle specific comprehensive women's health and maternal child health. J Korean Soc Matern Child Health. 2014;18(1):1-12.

[4] Choi JB. Urinary incontinence in women. KJFM. 2010;31(9):661-71.

[5] Cancer prevalence continues to rise, with a total of 1.74 million people living in the world. http://www.mohw. go.kr/react/al/sal0301vw.jsp? December 27, 2018.

[6] Sim MJ, Lee YS. Review of low back pain during pregnancy. J Korean Soc Matern Child Health. 2000; 4(2):271-82.

[7] Kim SY, Nam KW. A survey of characteristics and management of low back pain in postpartum women. PTK. 2002;9(1):69-79.

[8] Korea Physical Therapy Association Society Information, 2021. http://www.kpta.co.kr/center/intro/societyInfo
February 26, 2021.

[9] Notice of change in the scope of the national examination for physical therapists, 2020. https://www.kuksiwon or.kr/notice/brd/m_51/view.do? February 26, 2021.

[10] Han HJ. Current management for pregnancy-related low back pain by korean physical therapists: A National Cross-sectional Survey Using the Vignette Method. Master's Degree. Daejeon University. 2020.

[11] Hong SY. The survey on the awareness, interest and need of occupational therapy students for the dementia care center. JKCBOT. 2018;8(3):37-47.

[12] Seo SY, Kim SE. A survey of occupational therapists' recognition about rehabilitation robots. Korea Aging Friendly Industry Association. 2019;11(1):23-31.

[13] de Santana e Santos NA, Saintrain MVL, Regadas RP, et al. Assessment of physical therapy strategies for recovery of urinary continence after prostatectomy. Asian Pac J Cancer Preven. 2017;18(1):81-6.

[14] Lawson S, Sacks A. pelvic floor physical therapy and women's health promotion. J Midwifery Women's Health. 2018;63(4):410-7.

[15] Lee WS, Choi YS, Lee SJ, et al. Effects on physical symptoms, daily life problems, and sexual life problems of a urinary incontinence management program for women with mixed urinary incontinence. J Korean Clin Nurs Res. 2009;15(2):91-102.

[16] Kim UY. Predictors of the use of integrative health services among patients with breast cancer. Master's Degree. Hanyang University. 2012.

[17] Park DM, Moon HM, Kim JS. Therapeutic exercise for incontinence patients. J Kor Phys Ther. 1998;10(2): 183-93.

[18] Kim HT, Park BH, Young SB, et al. Low back pain in pregnancy. The Journal of the Korean Orthopaedic Association. 1993;28(3):1001-8.

[19] Kim YM, Rho HL. Awareness of physical therapy rehabilitation program after breast cancer surgery in healthy Korean women. J Korean Soc Phys Med. 
2018;13(1):39-47.

[20] Go SH, Kwon GR, Kim MS, et al. Awareness of marriage, childbirth, fertility and knowledge of high-risk pregnancy among university students. Korean Parent-Child Health Journal 2017;20(2):67-79.

[21] Kim HS, Park JS, Jo EJ. The perceptions of marriage and childbirth of health care fields college students. KJOHSM. 2011;5(2):131-46.

[22] Jeon GS, Choi ES, Lee HY. Gender-related difference in the utilization of health care services by Korean adults. J Korean Public Health Nurs. 2010;24(2):182-96.

[23] Kim SY, Kim CH, Song JY, et al. An investigation of factors which influence physical therapy students satisfaction with their clinical practice. KAUTPT. 2004;11(3):71-84.

[24] Park BS. A study on career preference after graduation of university students majoring in physical therapy. Master's Degree. Eulji University. 2012

[25] Kim SH. The study on the impact of social work practicum on career development-laying stress on vocational identity, career decision making status, and career preparation behavior-. Master's Degree. Ewha Womans University. 2007. 


\section{Appendix I-questionnaire}

\section{General Properties}

1. Please select your gender.

(1) Male (2) Female

2. Please write your age.

3. Please select your grade.

(1) First grade (2) Second grade (3) Third grade

(4) Fourth grade

4. Please indicate your university.

5. Do you have experience in clinical practice?

(1) Yes (2) No

5-1. If you answered yes, how long did you practice?

II. Awareness of WHPT (women's health physical therapy)

1. Do you know about women's health physical therapy?

(1) Very Yes (2) Yes (3) Average (4) Not entirely

(5) Not at all

1-1. If you answered 'very yes' or 'yes', which route did you learn from?

(1) Internet/TV (2) University education (3)

Book/Newspaper (4) Lecture (5) Other

1-2. If you answered 'very yes' or 'yes', what areas of women's health physical therapy do you know?

(1) Pregnancy and childbirth (2) Genital and gastrointestinal disease (3) Obesity (4) Cancer (5) Urinary

2. What do you think are the problems of providing women's health physical therapy?

(1) No difference from general physical therapy

(2) Lack of specialist of WHPT

(3) Lack of information about women disease

(4) Cost

(5) Other

3. What do you think is necessary to improve awareness of women's health physical therapy?

(1) Curriculum formation

(2) Workshop with other areas

(3) Advertising via media

(4) Professional certificate system

(5) Other

4. Do you think the role of a physical therapist is important in treating women's diseases?

(1) Very Yes (2) Yes (3) Average (4) Not entirely

(5) Not at all

III. Demands of WHPT (women's health physical therapy)

1. Do you think women's health physical therapy is necessary?

(1) Very Yes (2) Yes (3) Average (4) Not entirely

(5) Not at all

1-1. If you answered 'very yes' or 'yes', why?

(1) To provide high-quality care

(2) To expand the field of physical therapy

(3) To expand the subject of physical therapy

(4) Field of interest

1-2. If you answered 'Not at all', 'Not entirely', why?

(1) General physical therapy is enough

(2) Systematic program not developed

(3) Limitations of care program

(4) Negative outlook

2. Do you think you receive sufficient education and clinical practice about women's physical therapy at the university?

(1) Very Yes (2) Yes (3) Average (4) Not entirely

(5) Not at all

3. Are you willing to participate in education about women's health physical therapy?

(1) Very Yes (2) Yes (3) Average (4) Not entirely

(5) Not at all

4. Do you think positively about the outlook for 
women's health physical therapy?

(1) Very Yes (2) Yes (3) Average (4) Not entirely

(5) Not at all

5. After graduation, are you willing to work in a field related to women's health physical therapy?

(1) Very Yes (2) Yes (3) Average (4) Not entirely

(5) Not at all

5-1. If you answered 'very yes' or 'yes', why?

(1) To experience the field of women's health physical therapy

(2) For financial reasons
(3) Low competition rate

(4) For postgraduate course

5-2. If you answered 'Not at all' or 'Not entirely', why?

(1) Not interest field

(2) Low awareness of women's health physical therapy

(3) Low salary

(4) Competition for employment

(5) Unstable employment 